\section{Je mehr Allergene, desto weniger Ekzem?}

\author{
Die Zusammenhänge zwischen Innenraumallergenen und der Ent- \\ wicklung eines atopischen Ekzems sind nicht klar. Das könnte daran \\ liegen, dass der in vielen Studien gewählte Beobachtungszeitraum \\ von zwei oder drei Jahren zu kurz ist, um Korrelationen zu erkennen. \\ Britische Ärzte schlossen jetzt eine achtjährige Kohortenstudie ab.
}

$\mathrm{D}$ ie Daten von insgesamt 593 Kindern wurden von der Geburt bis zum Alter von acht Jahren dokumentiert. Die Eltern unterzogen sich im Rahmen der Rekrutierung einem Hauttest mit Allergenextrakten von Hausstaubmilben, Katzenhaaren und Gräserpollen. Außerdem wurden Angaben über Familiengröße und Lifestyle-Faktoren erhoben und acht Wochen nach der Geburt im Wohnzimmer gesammelte Staubproben auf Hausstaubmilben- und Katzenallergene untersucht. In jährlichen Abständen wurden die Kinder dann auf das Vorliegen eines atopischen Ekzems untersucht, im Alter von fünfeinhalb und acht Jahren wurden zusätzlich Hauttests durchgeführt.

Bis zum Alter von acht Jahren erfüllten 150 Kinder (25,3\%) mindestens einmal die diagnostischen Kriterien eines atopischen Ekzems. Dazu gehörten Hautjucken und mindestens drei weitere der folgenden Befunde: Beteiligung der

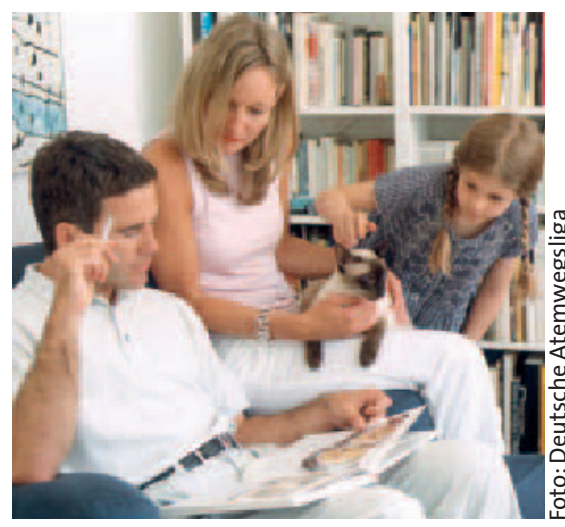

Der rauchende Vater ist ein Risikofaktor, die Mutter mit Katze dagegen eher nicht.
Beugeseiten, allgemein trockene Haut, allergische Erkrankungen bei Geschwistern oder Eltern oder sichtbare Dermatitis entsprechend photographischem Protokoll. 129 Kinder (28\%) litten mindestens einmal unter einer sichtbaren Dermatitis der Beugeseiten. Eine positive Allergieanamnese der Eltern war mit den meisten Ekzemkriterien positiv korreliert. Außerdem traten umso häufiger Ekzeme auf, je besser die Ausbildung der Mutter und je weniger beengt die Wohnverhältnisse waren. Keine klaren Zusammenhänge ergaben sich dagegen zwischen atopischem Ekzem und der frühen Exposition gegenüber Hausstaubmilbenund Katzenallergenen: Das Ekzemrisiko war aber in den drei untersten Quintilen der Milbenallergenexposition höher als in den beiden höheren Quintilen.

Fazit: Die bisherige Annahme, eine frühe hohe Allergenbelastung sei ein Hauptrisikofaktor für die Entwicklung eines atopischen Ekzems, wird in dieser Untersuchung nicht bestätigt.

$b k$

Harris JM et al. Early allergen exposure and atopic eczema. Br J Dermatol 2007; 156: 698-704

\section{Mehr Cortisol durch Glukokortikoide}

\section{Ein längerer Einsatz topischer Glukokortikoide beeinflusst die Hypo- thalamus-Hypophysen-Nebennierenrinden-Funktion und reduziert die endogene Cortisolproduktion, so bisherige Befürchtungen. Ein neuer Studienansatz stellt diesen Zusammenhang in Frage.}

W issenschaftler aus den Niederlanden untersuchten prospektiv zwei Gruppen von Patienten mit atopischer Dermatitis: Die erste Gruppe bestand aus 25 stationären Patienten mit schwerem, nicht kontrollierbarem atopischen Ekzem. Der zweiten Gruppe wurden 28 ambulante Patienten mit mäßigem bis schwerem, aber kontrolliertem atopischen Ekzem als Kontrolle zugeordnet. Die morgendlichen basalen Serumcortisolspiegel wurden in Gruppe eins bei Krankenhausaufnahme und bei -entlassung, in Gruppe zwei nur einmal bestimmt. Der Einsatz von topischen
Glukokortikoiden in den letzten drei Monaten vor der Cortisolmessung wurde dokumentiert, die Krankheitsaktivität anhand des „Six Area, Six Sign Atopic Dermatitis"-(SASSAD-)Score bestimmt.

80\% der Patienten der Gruppe eins hatten bei ihrer stationären Aufnahme signifikant erniedrigte basale Cortisolspiegel $(\mathrm{p}<0,001)$, bei 25 von 28 Patienten der Gruppe zwei waren diese dagegen normal. Im direkten Vergleich ergab sich in Gruppe eins zu Beginn der stationären Behandlung ein signifikant erniedrigter Cortisolspiegel $(\mathrm{p}<0,001)$. Gleichzeitig litten die Patienten der
Gruppe eins zu Behandlungsbeginn unter einer signifikant höheren Krankheitsaktivität als die von Gruppe zwei $(p<0,001)$. Die Gruppen unterschieden sich jedoch nicht im Verbrauch externer Glukokortikoide in den drei Monaten vor der Cortisolbestimmung. Bei Entlassung waren bei den Patienten der Gruppe eins das basale Cortisol trotz einer intensiven Glukokortikoidbehandlung signifikant angestiegen $(p<0,0001)$ und die Krankheitsaktivität signifikant $(\mathrm{p}<0,001)$ abgefallen.

Fazit: Bei schwerer atopischer Dermatitis scheint eher die Krankheitsaktivität als der Gebrauch externer Glukokortikoide die endogenen Cortisolspiegel zu beeinflussen.

$b k$

Haeck IM et al. Low basal serum cortisol in patients with severe atopic dermatitis: potent topical corticosteroids wrongfully accused. Br J Dermatol 2007; 156: 979-85 